\title{
Nailing versus plating in humerus shaft fractures: A prospective comparative study
}

\author{
Kiran Singisetti • M. Ambedkar
}

Received: 19 December 2008/Revised: 3 May 2009 /Accepted: 11 May 2009/Published online: 9 June 2009

(C) Springer-Verlag 2009

\begin{abstract}
There is a debate about the choice of operative intervention in humerus shaft fractures requiring surgical intervention. A prospective, comparative study of management of acute humeral shaft fractures treated by antegrade interlocking nail fixation and dynamic compression plating was undertaken over a period of three years. Twenty patients of interlocking nailing and sixteen patients of plating were included after considering the inclusion and exclusion criteria. Functional scoring criteria were used for postoperative assessment and the average follow-up period was one year. A higher rate of excellent and good results and a tendency for earlier union was seen with the plating group in our series.
\end{abstract}

\section{Background}

Fractures of the humeral shaft are commonly encountered by orthopaedic surgeons, accounting for approximately $3 \%$ of all fractures [20]. Treatment methods for these injuries continue to evolve as advances are made in both non-operative and operative management. It is generally agreed that most fractures of humeral shaft are treated best non-operatively, although there are indications for primary or secondary operative treatment in some situations $[8,18,19]$. The encouraging results that have been reported with recent advances in internal fixation techniques and instrumentation

K. Singisetti $(\bowtie)$

Trauma and Orthopaedics, University Hospital of North Tees, Stockton on Tees, TS19 8PE, United Kingdom

e-mail: kiransingisetti@gmail.com

K. Singisetti $\cdot$ M. Ambedkar

Trauma and Orthopaedics, King George Hospital,

Visakhapatnam, India have led to an expansion of surgical indications for such fractures and a dilemma about the procedure of choice.

\section{Materials and methods}

A prospective, comparative study of management of acute humeral shaft fractures by antegrade interlocking nail fixation and dynamic compression plating was undertaken at our institution over a period of three years (November 2001 to November 2004). The average follow-up period was one year (range 10-24 months). An informed consent from patients and departmental permission were obtained according to local hospital regulations.

Forty-five patients with closed acute humeral shaft fracture requiring operative intervention were treated with either interlocking nailing or plating procedures. A randomisation attempt was made by allocating each patient to either of the groups depending on the criteria of odd or even hospital number.

The inclusion criteria were: (1) humeral shaft fractures which required operative intervention and were treated with interlocking or plating procedures, and (2) patients of age of 18 years or more.

The exclusion criteria were: (1) the patient was aged less than 18 years, (2) pathological fractures, (3) segmental fractures, (iv) fractures within $4 \mathrm{~cm}$ of proximal and distal end of humerus, and (5) patients who were lost to follow-up or at early stages of follow-up at the time of completion of the study (minimum follow up of six months required).

All patients had appropriate clinical and radiological assessment before a decision to offer surgical intervention was made. All fractures were classified according to the AO classification. Of the 25 patients treated by interlocking nail, three were at early stage follow-up and two were lost 
Table 1 Criteria for evaluating functional results

\begin{tabular}{|c|c|c|c|c|}
\hline Rating & Elbow range of movement & Shoulder range of movement & Pain & Disability \\
\hline Excellent & $\begin{array}{l}\text { Extension } 5^{\circ} \\
\text { Flexion } 130^{\circ}\end{array}$ & Full range of movement & None & None \\
\hline Good & $\begin{array}{l}\text { Extension } 15^{\circ} \\
\text { Flexion } 120^{\circ}\end{array}$ & $<10 \%$ loss of total range of movement & Occasional & Minimum \\
\hline Fair & $\begin{array}{l}\text { Extension } 30^{\circ} \\
\text { Flexion } 110^{\circ}\end{array}$ & $10-30 \%$ loss of total range of movement & With activity & Moderate \\
\hline Poor & $\begin{array}{l}\text { Extension } 40^{\circ} \\
\text { Flexion } 90^{\circ}\end{array}$ & $>30 \%$ loss of total range of movement & Variable & Severe \\
\hline
\end{tabular}

Table 2 Age incidence

\begin{tabular}{lll}
\hline Age group (y) & Number of patients & Percentage \\
\hline $11-20$ & 1 & $2.7 \%$ \\
$21-30$ & 10 & $25 \%$ \\
$31-40$ & 15 & $41 \%$ \\
$41-50$ & 6 & $16.6 \%$ \\
$51-60$ & 3 & $8.3 \%$ \\
$61-70$ & 1 & $2.7 \%$ \\
$71-80$ & 0 & $0 \%$ \\
\hline
\end{tabular}

Table 3 Indications for operative management

\begin{tabular}{llc}
\hline Indications & Number of patients & Percentage \\
\hline Humeral fractures with multiple injuries & 10 & $27.77 \%$ \\
Fractures with unacceptable reduction & 19 & $52.77 \%$ \\
Secondary displacement of fracture reduction with non-operative treatment (before 6 weeks) & 5 & $13.88 \%$ \\
Open fractures & 1 & $2.77 \%$ \\
Pathological fractures & 0 & $0 \%$ \\
Humeral with ipsilateral forearm fractures & 1 & $2.77 \%$ \\
\hline
\end{tabular}

Table 4 Complications of interlocking nail

\begin{tabular}{lll}
\hline Complications & Number of patients & Percentage \\
\hline Fissure/avulsion at insertion point & 0 & $0 \%$ \\
Opening of splinter at fracture site & 3 & $15 \%$ \\
Radial nerve palsy & 0 & $0 \%$ \\
Infection & 1 & $5 \%$ \\
Delayed union (>16 weeks) & 10 & $50 \%$ \\
Nonunion with bending of nail & 1 & $5 \%$ \\
Restriction of shoulder ROM & 3 & $15 \%$ \\
Restriction of elbow ROM & 0 & $0 \%$ \\
\hline
\end{tabular}


Table 5 Complications of plating

\begin{tabular}{lll}
\hline Complication & Number of patients & Percentage \\
\hline Infection & 2 & $12.5 \%$ \\
Radial nerve palsy & 1 & $6.25 \%$ \\
Delayed union (>16 weeks) & 4 & $25 \%$ \\
Nonunion & 1 & $6.25 \%$ \\
Implant failure & 0 & $0 \%$ \\
\hline
\end{tabular}

to follow-up at completion of the study. Of the 20 patients treated by plating, two were in early follow-up and two lost to follow-up.

After applying the inclusion and exclusion criteria, we included 20 patients of interlocking nailing and 16 patients of plating for final analysis in the study.

An antegrade interlocking technique was used with an intramedullary nail (Russell-Taylor type) and care was taken to minimise damage of the rotator cuff during nail insertion. A 3.5-mm or 4.5-mm dynamic compression plate was used in the plating group depending on the width of the bone with appropriate AO principles. The choice of surgical approach (antero-lateral or posterior) for the plating group was left to the discretion of the operating surgeon.

All patients were advised on immediate postoperative shoulder and elbow exercises and radiographs were taken at regular intervals during follow-up. Rodriguez-Merchan criteria (1995) were used to compare the postoperative results of interlocking nailing and plating procedures at follow-up. It was originally described for comparison of compression plating versus Hackethal nailing in closed humeral shaft fractures [16]. The overall rating of excellent, good, fair and poor outcomes was based on scores of shoulder and elbow movements along with pain and disability after the procedure (see Table 1). In situations where any two different criteria fell into separate categories, the lower category was selected to classify the outcome.

\section{Results}

\section{Demographics}

The youngest in our series was 18 years old while the oldest was 63 years. The maximum incidence was seen in age groups 21-30 and 31-40 years (see Table 2). Males accounted for $77 \%$ and no obvious side predilection was

Table 6 Time taken for union with interlocking nail

\begin{tabular}{lll}
\hline Time taken for union & Number of patients & Percentage \\
\hline$<16$ weeks & 10 & $50 \%$ \\
$>16$ weeks & 10 & $50 \%$ \\
\hline
\end{tabular}

Table 7 Time taken for union with plating

\begin{tabular}{lll}
\hline Time taken for union & Number of patients & Percentage \\
\hline$<16$ weeks & 12 & $75 \%$ \\
$>16$ weeks & 4 & $25 \%$ \\
\hline
\end{tabular}

noted. Road traffic accidents accounted for about $85 \%$ of the fractures followed by domestic and other causes. All of the fractures could be grouped as A3 and B2 of AO classification, and $64 \%$ involved the middle third of the humerus shaft. Associated medical problems included hypertension in three patients, ischemic heart disease in one patient and diabetes mellitus in two patients.

Indications

More than half of the patients in our study needed operative intervention due to failure of acceptable fracture reduction and alignment by closed methods (see Table 3 ).

\section{Complications}

Preoperative radial nerve palsy was seen in four cases $(11.11 \%)$ in our series. All cases of preoperative radial nerve palsy recovered completely following stabilisation, indicating a neuropraxia type of injury. The radial nerve was explored to check its integrity in only two cases where open reduction was done for plating. No postoperative radial nerve palsy was seen in the interlocking nailing group. Postoperative radial nerve palsy was seen in one case in the plating group (6.25\%) (see Tables 4 and 5).

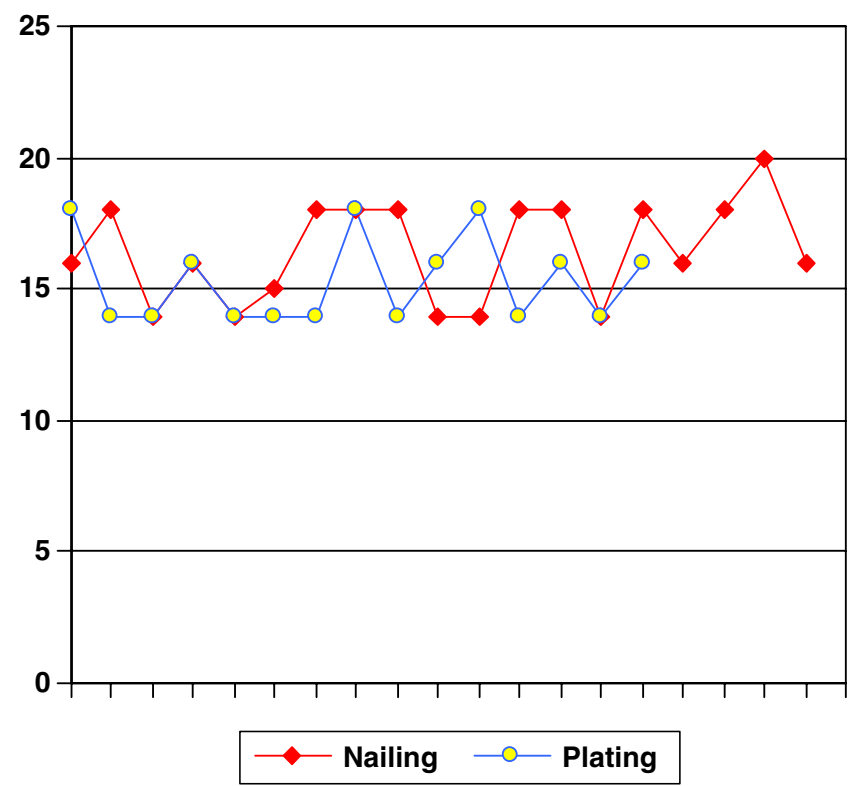

Graph 1 Time for union in weeks for interlocking nail versus plating 
Table 8 Results of interlocking nail (Rodriguez-Merchan criteria)

\begin{tabular}{lll}
\hline Result & Number of patients & Percentage \\
\hline Excellent & 4 & $20 \%$ \\
Good & 9 & $45 \%$ \\
Fair & 5 & $25 \%$ \\
Poor & 2 & $10 \%$ \\
\hline
\end{tabular}

There was one case of deep infection each in the plating $(6.25 \%)$ and interlocking groups (5\%). Both were controlled by washout and continued use of antibiotics and eventually went on to union. The interlocking nail patient with infection was left with severe adhesive capsulitis and an overall poor result.

Time for union

Fifty percent of interlocking nail patients and 75\% of plating patients showed evidence of union on or before 16 weeks (Tables 6 and 7, Graph 1). This difference was found to be statistically significant on Students $t$ test $(p<0.05)$. One case of interlocking nailing had nonunion (5\%) with bending of a nail, which was treated by closed exchange nailing with reaming. One case of nonunion plating $(6.25 \%)$ was treated by bone grafting as a secondary procedure.

\section{Functional results}

Thirteen out of 20 patients of the interlocking nail group had good to excellent results while 15 out of 16 patients of the plating group had similar results at the final follow-up for the study. This difference was found to be statistically significant on Students $t$ test $(p<0.05)$ (see Tables 8 and 9, Graph 2, Figs. 1 and 2).

\section{Discussion}

The common indications for operative treatment in our series were failure to achieve acceptable reduction by closed methods and patients with multiple injuries. Accepted indications for surgical management of humeral shaft fractures are (i) unsatisfactory alignment or reduction by nonoperative methods, (ii) associated injuries in the extremity

Table 9 Results of plating (Rodriguez-Merchan criteria)

\begin{tabular}{lll}
\hline Result & Number of patients & Percentage \\
\hline Excellent & 4 & $25 \%$ \\
Good & 11 & $68.75 \%$ \\
Fair & 0 & $0 \%$ \\
Poor & 1 & $6.25 \%$ \\
\hline
\end{tabular}

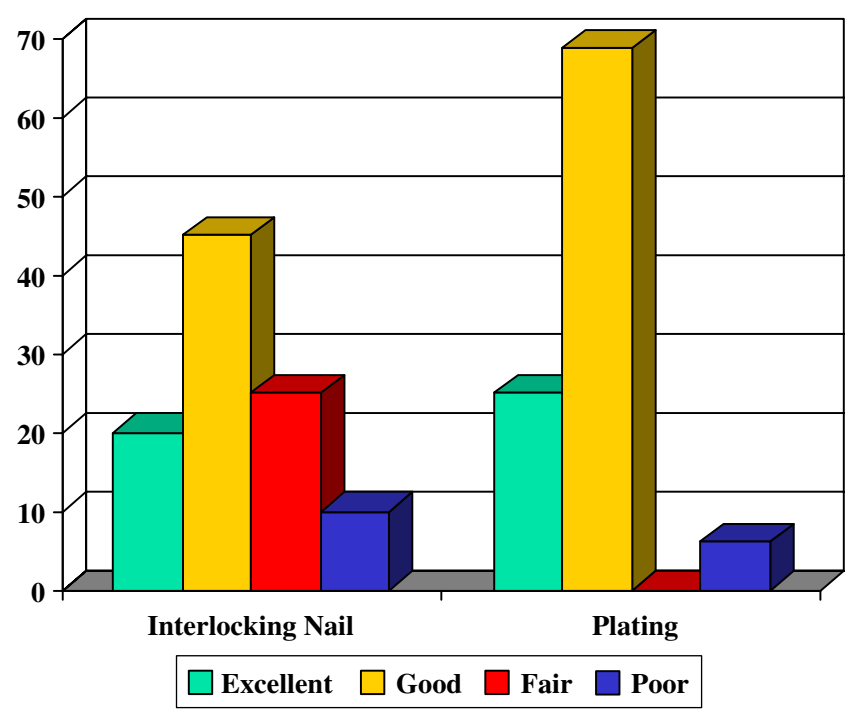

Graph 2 Results of interlocking nail versus plating

requiring early mobilisation, (iii) segmental fracture, (iv) pathological fracture, (v) fracture associated with major vascular injuries, (vi) humeral fractures with radial nerve palsy developing after manipulation or application of cast, (vii) polytrauma and (viii) floating elbow [2, 8, 9, 11, 19].

Humeral shaft fractures have been reported to be more common in males with a peak incidence in the third decade [20]. Road traffic accident was a common cause for such fractures in our and other similar studies [20]. A variation in epidemiological features of humeral shaft fractures is noted with different geographical locations [11, 19, 20].

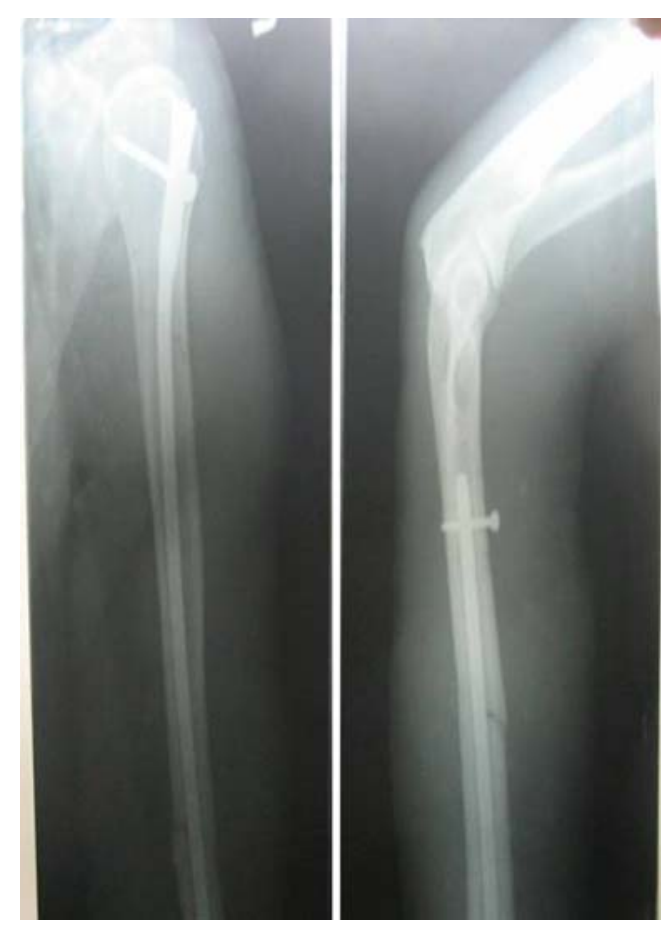

Fig. 1 Radiograph of good results with interlocking nailing 
Fig. 2 a Radiograph of poor results with bending of interlocking nail. b Radiograph after exchange nailing
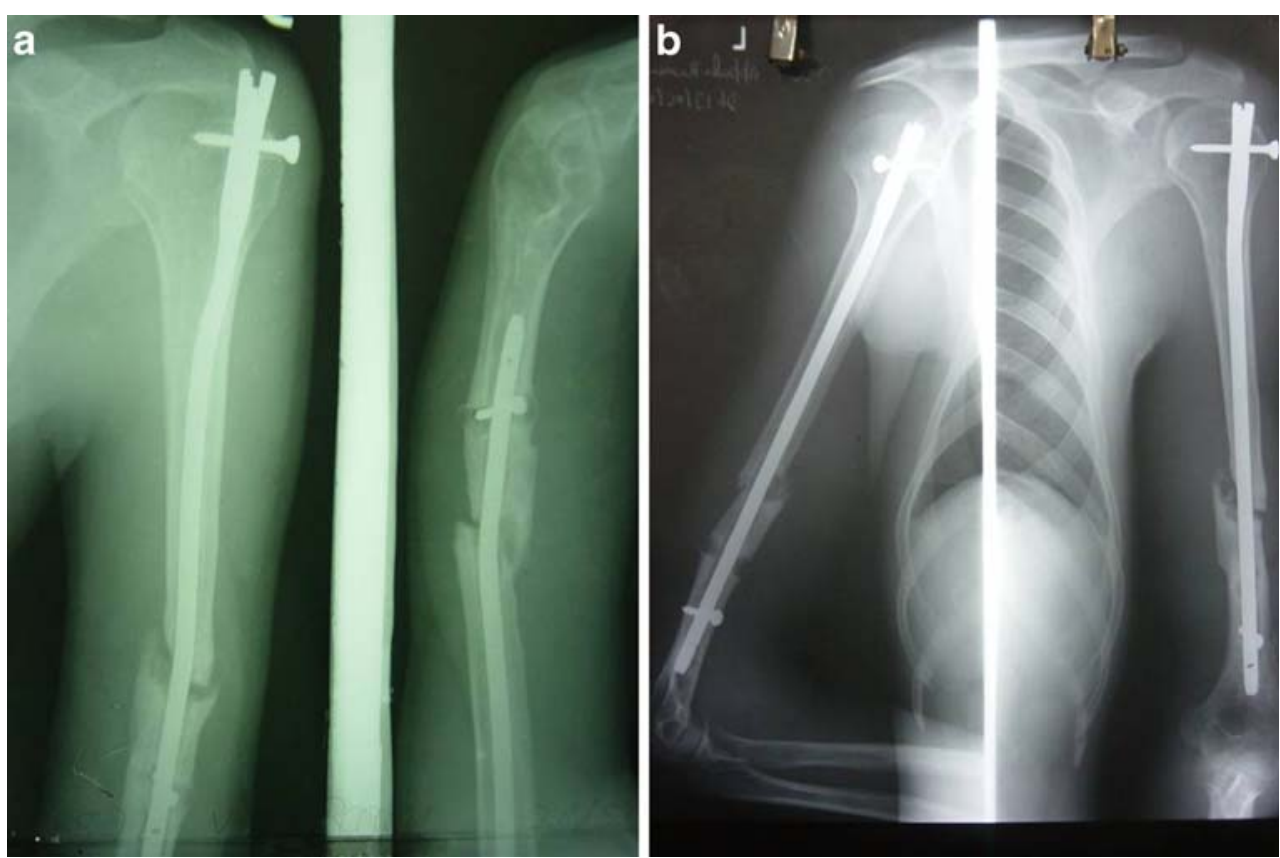

While there are several methods of operative intervention for humerus shaft fractures, the internal fixation methods can be broadly grouped as plating or intramedullary techniques. Interlocking nailing is preferable in communited, segmental and pathological fractures while plating may be the preferred option where radial nerve exploration is contemplated $[5,13$, 14]. Conventional plating techniques involve an extensive surgical approach for open reduction of fracture. But encouraging results from minimally invasive plating methods have been reported recently $[1,10,12]$. The external fixation technique is less popular in treatment of humeral shaft fractures and may be used in open injuries [19].

Infection, nonunion and radial nerve palsy are general concerns suggested in the plating group $[4,9,16]$. But in a published meta-analysis, results of plate fixation from pooled data did not show higher risks of nonunion, infection, or radial nerve palsy [3]. Restriction of shoulder movements and risk of delayed union have been suggested as concerns with the intramedullary techniques $[3,4,7,9,13,16]$. Impairment of shoulder function with the antegrade interlocking nails could be because of impingement due to proximal migration of nail, rotator cuff violation, adhesive capsulitis or due to an unexplained cause $[6,7,15,17]$. This problem can be potentially minimised by using a retrograde technique but carries a risk of elbow movement restriction and fracture at the insertion point $[4,9,15]$. Some report increased incidence of elbow stiffness with the plating group [7].

The higher rate of excellent and good results with the plating group patients seen in our series was also cited in many other reports $[13,15]$. But another series has suggested that both groups had predictable results and neither of them is markedly superior [7]. In a recent study, no difference between the two groups in terms of the rate of union and functional outcome but a shorter union time with interlocking was suggested [6]. This was in contrast to our study which reflects earlier union time with the plating procedure.

In conclusion, no single treatment option is superior in all circumstances for a particular fracture and each case has to be individualised. Plating has been shown to have better overall results compared to the interlocking nails in treatment of closed humeral shaft fractures. A tendency for earlier union is seen with the plating group.

Conflict of interest None to declare.

\section{References}

1. An Z, Zeng B, He X, Chen Q, Hu S (2009) Plating osteosynthesis of mid-distal humeral shaft fractures: minimally invasive versus conventional open reduction technique. Int Orthop Epub Mar 20

2. Bell MJ, Beauchamp CG, Kellam JK, McMurtry RY (1985) The results of plating humeral shaft fractures in patients with multiple injuries. The Sunnybrook experience. J Bone Joint Surg Br 67 (2):293-296

3. Bhandari M, Devereaux PJ, McKee MD, Schemitsch EH (2006) Compression plating versus intramedullary nailing of humeral shaft fractures - a meta-analysis. Acta Orthop 77(2):279-284

4. Brumback RJ, Bosse MJ, Poka A, Burgess AR (1986) Intramedullary stabilization of humeral shaft fractures in patients with multiple trauma. J Bone Joint Surg Am 68(7):960-970

5. Chao TC, Chou WY, Chung JC, Hsu CJ (2005) Humeral shaft fractures treated by dynamic compression plates, Ender nails and interlocking nails. Int Orthop 29(2):88-91

6. Changulani M, Jain UK, Keswani T (2007) Comparison of the use of the humerus intramedullary nail and dynamic compression 
plate for the management of diaphyseal fractures of the humerus. A randomised controlled study. Int Orthop 31(3):391-395

7. Chapman JR, Henley MB, Agel J, Benca PJ (2000) Randomized prospective study of humeral shaft fracture fixation: Intramedullary nails versus plates. J Orthop Trauma 14:162-166

8. Foster RJ, Dixon GL Jr, Bach AW, Appleyard RW, Green TM (1985) Internal fixation of fractures and non-unions of the humeral shaft. Indications and results in a multi-center study. J Bone Joint Surg Am 67(6):857-864

9. Hall RF Jr, Pankovich AM (1987) Ender nailing of acute fractures of the humerus. A study of closed fixation by intramedullary nails without reaming. J Bone Joint Surg Am 69(4):558-567

10. Ji F, Tong D, Tang H, Cai X, Zhang Q, Li J, Wang Q (2009) Minimally invasive percutaneous plate osteosynthesis (MIPPO) technique applied in the treatment of humeral shaft distal fractures through a lateral approach. Int Orthop 33(2):543-547

11. Klenerman L (1966) Fractures of the shaft of the humerus. J Bone Joint Surg Br 48(1):105-111

12. Livani B, Belangero W, Andrade K, Zuiani G, Pratali R (2008) Is MIPO in humeral shaft fractures really safe? Postoperative ultrasonographic evaluation. Int Orthop Epub Aug 13

13. McCormack RG, Brien D, Buckley RE, McKee MD, Powell J, Schemitsch EH (2000) Fixation of fractures of the shaft of the humerus by dynamic compression plate or intramedullary nail: A prospective randomized trial. J Bone Joint Surg Br 82(3):336-339

14. Pollock FH, Drake D, Bovill EG, Day L, Trafton PG (1981) Treatment of radial neuropathy associated with fractures of the humerus. J Bone Joint Surg Am 63(2):239-243

15. Raghavendra S, Bhalodiya HP (2007) Internal fixation of fractures of the shaft of the humerus by dynamic compression plate or intramedullary nail: A prospective study. Indian J Orthop 41 (3):214-218

16. Rodríguez-Merchán EC (1995) Compression plating versus Hackethal nailing in closed humeral shaft fractures failing nonoperative reduction. J Orthop Trauma 9(3):194-197

17. Stern PJ, Mattingly DA, Pomeroy DL, Zenni EJ Jr, Kreig JK (1984) Intramedullary fixation of humeral shaft fractures. J Bone Joint Surg Am 66(5):639-646

18. Sarmiento A, Kinman PB, Galvin EG, Schmitt RH, Phillips JG (1977) Functional bracing of fractures of the shaft of the humerus. J Bone Joint Surg Am 59A:596-601

19. Sarmiento A, Waddell JP, Latta LL (2002) Diaphyseal humeral fractures: Treatment options. Instr Course Lect 51:257-269

20. Tsai $\mathrm{CH}$, Fong $\mathrm{YC}$, Chen $\mathrm{YH}$, Hsu CJ, Chang $\mathrm{CH}$, Hsu HC (2009) The epidemiology of traumatic humeral shaft fractures in Taiwan. Int Orthop 33(2):463-467 